\title{
Advances in Studies on Horizontal Gene Transfer Promoting the Evolution of Resistance Genes of Periodontal Pathogens
}

\author{
Li Jianbin ${ }^{1,2}$, Yu Xijiao ${ }^{2,3, *}$ \\ ${ }^{1}$ School of Stomatology, Binzhou Medical University, Yantai, China \\ ${ }^{2}$ Central Laboratory, Jinan Hospital of Stomatology, Jinan, China \\ ${ }^{3}$ Department 2 of Endodontics, Jinan Hospital of Stomatology, Jinan, China
}

Email address:

1105062747@qq.com (Jianbin Li), yayiyu@163.com (Xijiao Yu)

${ }^{*}$ Corresponding author

\section{To cite this article:}

Li Jianbin, Yu Xijiao. Advances in Studies on Horizontal Gene Transfer Promoting the Evolution of Resistance Genes of Periodontal Pathogens. Science Discovery. Vol. 9, No. 5, 2021, pp. 255-262. doi: 10.11648/j.sd.20210905.19

Received: September 29, 2021; Accepted: October 25, 2021; Published: November 5, 2021

\begin{abstract}
Horizontal gene transfer (HGT) plays an important role in bacterial evolution. HGT is an important way for bacteria to rapidly obtain genetic improvement. HGT promotes the transmission of biological characteristics such as virulence, antibiotic resistance and allometabolism in microorganisms. The bacteria in the mouth are abundant and abundant. Bacterial virulence gene (Virulence genes, VGs) and antibiotic resistance genes (Antibiotic resistance genes, ARGs) besides through vertical transmission by parental, also can through HGT in oral symbiotic species or genus within the transmission. HGT promotes the spread of virulence genes and resistance genes, becomes an important driving force for the adaptive evolution of oral microorganisms, increases the difficulty of the treatment of oral bacterial infectious diseases (periodontal disease, periradicular lesions, Periimplantitis, etc.), and brings serious harm to human oral health and even general health. With modern microbiology, genetics, molecular biology, the macro development of disciplines, such as genomics, electron microscope and laser confocal microscope, nucleic acid hybridization (especially the 16 sRNA gene sequencing) and other modern analysis technology has been widely applied in periodontal pathogens resistance genes, through the study of HGT way spread and made some progress. This paper will analyze and summarize the literature on the spread of resistance genes of common periodontal pathogens through HGT method in recent years, in order to provide reference for the follow-up study of resistance of periodontal pathogens, as well as for the solution of resistance of periodontal pathogens and the treatment of periodontal diseases.
\end{abstract}

Keywords: Horizontal Gene Transfer, Antibiotic Resistance Or Antimicrobial Resistance, Periodontal Pathogens, Antibiotic Resistance Genes

\section{水平基因转移促进牙周致病菌抗性基因进化的研究进展}

\author{
李建斌 ${ }^{1,2}$, 于西佼 ${ }^{2,3 *}$ \\ 1 滨州医学院口腔医学院, 烟台, 中国 \\ 2济南市口腔医院中心实验室, 济南, 中国 \\ 3济南市口腔医院牙体牙髓病2科, 济南, 中国 \\ 邮箱 \\ 1105062747@qq.com(李建斌), yayiyu@163.com(于西佼)
}




\begin{abstract}
摘要: 水平基因转移(Horizontal gene transfer, HGT)在细菌进化中具有重要意义。HGT是细菌快速获得基因改良的重 要途径, HGT促进诸如毒力、抗生素耐药性和异源代谢等生物特性在微生物中进行传播。口腔内细菌种类丰富, 数 量巨大。细菌毒力基因 (Virulence genes,VGs) 和抗生素抗性基因 (Antibiotic resistance genes, ARGs)除了通过由亲代 垂直传播获得外, 亦可以通过HGT在口腔共栖菌属间或属内进行传播。HGT促进了毒力基因和抗性基因的传播, 成 为口腔微生物适应性进化的重要驱动力, 增加了口腔细菌感染性疾病 (牙周病, 根尖周病、种植体周围炎等) 的治疗 难度, 给人类口腔健康乃至全身健康带来严重危害。随着现代微生物学、遗传学、分子生物学、宏基因组学等学科的 发展, 电子显微镜、激光共聚焦显微镜、核酸杂交（特别是16SrRNA基因测序）等现代分析技术被广泛应用于牙周致 病菌耐药基因通过HGT方式播散的研究, 并取得一些进展。本文将对近年来有关常见牙周致病菌的耐药基因通过HGT 方式播散的文献进行分析总结, 以期能为牙周致病菌的耐药性问题的后续研究提供参考, 并为牙周致病菌耐药性问题 的解决以及牙周病的治疗提供参考。
\end{abstract}

关键词: 基因水平转移, 抗生素耐药性, 牙周致病菌, 抗生素抗性基因

\section{1. 引言}

抗生素的发现为人类对抗细菌感染性疾病带来了福 音, 但随着抗生素的不合理应用, 抗生素耐药问题已经成 为全球性医疗健康和环境健康问题。临床医疗, 动物养殖, 抗生素生产等人类活动中抗生素的不当使用均能促进抗 生素耐药菌株的产生和增加, 综合因素作用下使人类解决 抗生素耐药性问题更加棘手 [1]。携带抗生素抗性基因 (Antibiotic resistance genes, ARGs)和毒力基因 (Virulence genes, VGs) 的移动遗传元件 (Mobile genetic element, MGE) 可以通过HGT在菌株间进行转移, 促进了抗生素 耐药性、毒力的传播 [2], 现已明确菌株通过HGT获得新的 基因是细菌进化的重要方式之一[3]。口腔作为人体五大菌 库之一, 口腔内细菌种类丰富, 近年来关于口腔内抗生素 耐药菌株的的研究不断深入, 特别是在HGT促进ARGs的 传播方面[4], 取得了一些的新进展, HGT促进了毒力基因 和抗性基因的传播, 进一步增加了口腔复杂细菌感染性疾 病（重度牙周炎、难治性根尖周炎以及口腔领面部的多重 耐药菌感染）的治疗难度。

牙周病是一种以牙菌斑生物膜为始动因素的感染性 疾病, 抗生素是中重度牙周炎必不可少的辅助治疗手段。 在抗生素的选择压力下, 推动了 $\mathrm{ARG}$ 的获得和进化, 危及 口腔感染性疾病的抗生素治疗效果, 还会危及由于细菌异 位引起的口腔外感染的控制[5]。本文将对近年来有关常见 牙周致病菌的抗性基因通过HGT方式进行播散的相关文 献进行综述, 探讨HGT促进牙周致病菌抗性基因进化机制, 以期能为牙周致病菌抗生素耐药性问题的后续研究提供 依据。

\section{2. 水平基因转移（HGT）的定义及其形式}

\section{1. 细菌HGT的定义}

HGT是指在差异性生物个体(同种但含有不同的遗传 信息的生物个体,或者是远缘（sobrinus）,甚至没有亲缘关 系的生物个体)之间,或单个细胞内部细胞器之间进行的遗 传物质的交流[6]。HGT是相对于垂直基因转移（具有“血 缘关系”的亲代将遗传物质传递给子代）而言的, HGT是 从亲代以外获得遗传物质的过程, 在细菌进化中具有重要
作用。特别是, HGT提供了快速获得基因改良的途径, 允 许诸如毒力、抗生素耐药和异源代谢等特性在人类微生物 群中传播[7], 是微生物进化过程中获得适应生存环境基因 的一种重要方式。

\section{2. 细菌HGT的形式}

现已明确 HGT 的主要形式有三种：1. 转化 (transformation), 是指将外源DNA分子 (DNA碎片、染色 体形式的循环核酸、噬菌体携带的宿主细胞来源的完整质 粒) 引入受体细胞, 从而获得新的遗传性状。自然环境中 处于天然感受态的细菌可以发生自然转化; 2. 接合 (conjugation), 是以接合质粒或接合转座子为载体的接 触依赖性DNA转移机制, 该方式是大多数细菌进行基因水 平转移的方式。细菌通过由接合质粒编码的性菌毛发生菌 株间染色体DNA或质粒DNA转移,进行基因重组。在接合 过程中,性菌毛将供体菌和受体菌连接在一起,使它们的细 胞壁接触,供体菌的DNA即可进入受体菌。例如, IV型分 泌系统 (Type IV secretion systems,T4SSs) 是革兰氏阴性 (Gram-negative,G-)和革兰氏阳性(Gram-Positive, G+)细菌 中的多蛋白复合功能系统, 负责在不同物种之间通过接合 转移传播抗生素抗性和毒力因子 [8]; 3.转导(transduction), 是以噬菌体为。

a. 转化

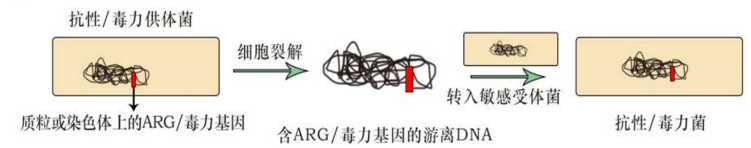

b. 接合

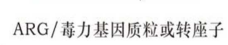
c. 转导

被ARG/毒力基因㗪菌体侵染的细菌

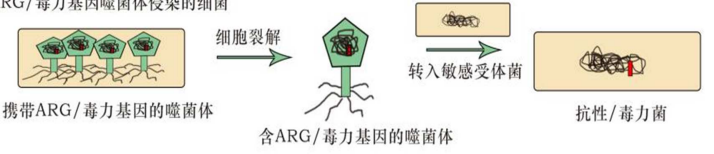

图1 细菌HGT的三种形式: a. 转化, b. 接合, c. 转导[9]。 
媒介将细菌的DNA从供体细胞转移到受体细胞中, 在 转导过程中通过 $\mathrm{F}^{\prime}$ 因子以接合形式将某个基因片段传递 给受体, 即宿主DNA被包裹在噬菌体中, 噬菌体作为载体 将其注入受体细胞（见图1）。Gena等[10]发现口腔中牙 龁卟啉单胞菌 (Porphyromonas gingivalis, P.gingivalis) 发生了染色体DNA水平转移, 证实由编码DNA解旋酶基 因 com F介导的自然转化是其染色体DNA转移的主要形式, 而通过类似接合机制发生的DNA转移起次要作用。

\section{3. 细菌水平基因转移（HGT）与抗生素耐药性}

HGT极大促进了抗生素耐药基因的广泛传播, 但目前 人们对于抗生素耐药基因的传播动力学机制知之甚少。当 ARGs通过以上途径在菌株间或与其他物种之间发生HGT, ARGs便成为相关传染性疾病爆发蔓延的始动因素。

\subsection{HGT与抗生素耐药}

全球范围内因多重耐药菌感染导致每年至少 70 万人 死亡。预计 30 年后, 全球每年死于抗药性感染人数将达到 1 亿, 这大大超过了因癌症死亡的人数 [11]。抗生素可以杀 灭其敏感微生物种群, 减少耐药菌竞争对手, 致使耐药菌 获得更多可用资源并不断增殖蔓延。预计到2050年，抗生 素抗药性将成为医疗保健领域的最大挑战。 $[12,13]$

当细菌面临抗生素的选择压力时, 可通过HGT获取 $\mathrm{ARG}$,使基因组改良优化, 提高其对生存环境的适应性。 细菌通过HGT可以比自发性突变更快地获取生存所必需 的基因 [14], 并通过HGT共享利于细菌生存、致病的基因 组 $[15,16]$ 。HGT还可以通过传播致病性状 (例如毒力和形 成生物膜的能力) 来促进感染播散和疾病爆发 [17]。研究 表明, 诸多环境因素通过影响质粒复制、改变噬菌体活性、 调节HGT相关酶的活性以及破坏免疫系统来调节 HGT [18], 从而影响细菌的抗生素耐药性和致病性 $[19,20]$ 。

\section{2. 水平基因转移（HGT）与口腔常用抗生素的耐药性}

口腔微生物组是一个物种丰富的微生物集合, 该集合 中各种菌株间形成共生、竞争或拮抗关系, HGT使口腔细 菌之间的联系更加密切, 有学者发现了存在于口腔菌斑生 物膜中的非口腔正常菌群释放的DNA可以转移到共生菌 内[21]。近些年来抗生素的不规范使用导致口腔致病菌对 各类常用抗菌药耐药性有所增加, 国内外学者在牙周炎和 牙龈炎以及配戴全口义齿患者的口腔中频繁检测出含有 抗性基因的微生物, 这些微生物常与多重耐药有关。

口腔微生物生态群作为人体最重要的微生物生态群之 一, 无疑成为耐药基因的储存库。质粒在口腔中广泛存在, 其中包括潜在可动员的多重耐药大质粒[22]。口腔耐药菌株 可以抵抗抗生素的杀灭, 并且可以通过HGT将ARGs进行转 移和传播, 例如, 口腔中四环素抗性基因 tet (M) 在不同耐 药菌株中的核苷酸水平的相似度超过 $95 \%$, 这证明 tet（M) 很可能通过HGT进行了交换, 并造成更多口腔细菌对四环素 产生耐药[23]。Tn916接合转座子在口腔中编码 $\operatorname{tet}(\mathrm{M})$ 引起的 四环素的耐药性 [24]。口腔菌斑和唾液中富含噬菌体 [25], 这对于口腔细菌间发生HGT是至关重要的.来源于细菌分泌
或者死亡裂解的eDNA是菌斑基质的重要组成部分, 能够通 过自然转化将携带的DNA片段传递给受体细菌, 最近研究发 现, 与口腔生物膜形成相关的变形链球菌以膜泡形式将 eDNA释放到正在形成的生物膜中, 为自然转化提供了一个 重要的遗传物质来源[26]。

Ramos等[27]评估了牙龁炎、牙周炎、牙周健康和戴 全口义齿患者口腔中对四环素和 $\beta$-内酰胺类抗生素耐药 的肠道细菌和假单胞菌的发生情况。发现了 $\beta$-内酰胺酶的 产生和四环素耐药性相关的耐药性标记的存在。龈下菌斑 是发生 $\beta$-内酰胺抗性基因水平转移的理想环境, 西班牙学 者Arredondo $\mathrm{A}[28]$ 对130名牙周炎患者龈下样本进行分离 鉴定, 获得了来自 35 个不同属的 737 个分离株。 $\beta$-内酰胺 耐药性在牙周炎患者中普遍存在, $83 \%$ 的患者中发现了 $\beta-$ 内酰胺耐药菌株。 $24.8 \%$ 的分离株中检测到抗性基因 blaCfxA, 其次是blaTEM (12.9\%)。大多数分离株 $(81.3 \%)$ 具有多重耐药性, 该学者认为龈下共生微生物群可能是多 药耐药性和 $\beta$-内酰胺酶基因的储存库。 $\beta$-内酰胺耐药性高 发生率可能与其相关抗性基因的HGT密切相关。

核糖体保护蛋白 (ribosomal protection proteins,RPPs) 是细菌对四环素产生耐药的决定因素, 在口腔致病菌中编 码这些蛋白质的耐药基因包括 $\operatorname{tet}(\mathrm{M})$ 、 tet $(\mathrm{O})$ 、 tet $(\mathrm{Q})$ 和 $\operatorname{tet}(\mathrm{W})$ 。其中以 $\operatorname{tet}(\mathrm{M})$ 最为常见, $\operatorname{Tet}(\mathrm{M})$ 在不同耐药菌株中 核苷酸水平上高度同源性表明该基因很可能通过HGT获 得和交换[23], 并得到证实[29]。此外tet(O)基因对核糖体 保护蛋白的产生也很重要, 该基因在健康婴儿口腔链球菌 中检测到 [29], tet $(O)$ 的获得不排除通过HGT获得的可能。

口腔细菌获得耐药基因 $\operatorname{mef}(\mathrm{A} / \mathrm{E})$ 基因产生了对 14 元 和15元大环内酯类化合物(14- and 15-membered macrolide compounds)的抗性, 该基因分为两个亚型, 分别为 mefA 和mefE, 有学者将口腔链球菌对大环内酯类抗生素进行耐 药基因的检测, 以肺炎链球菌R6为受体进行转化分析, 结 果显示抗性基因 $\operatorname{Mef}(\mathrm{E})$ 基因可以从链球菌中水平转移到 肺炎链球菌R6中[30]。

现已明确的口腔细菌对甲硝唑产生抗药性的两个耐药 基因nimA和nimB, 赋予了耐药菌中度到高度的耐药性 [31], 目前对于口腔细菌针对甲硝唑的耐药性比例较低, 且地域比 较局限。Xie Y等[32]对当地志愿者总共 41 个牙周脓肿样本中 的厌氧菌进行分离培养, 培养鉴定结果显示培养出 60 个不同 的细菌菌落, 通过PCR检测发现了nimB基因的存在。针对口 腔致病菌对于甲硝唑抗性基因发生HGT的证据有待于进一 步发现。HGT的发生受到生物、环境等诸多因素影响, 贯穿 于时间维度和空间维度之中, 不同学者针对口腔细菌对相同 抗生素耐药性的调查结果存在一定地域差异, 这种差异可能 是由不同地区抗生素应用情况的差异性导致的, 但有学者通 过对部分未曾使用过抗生素的原始部落的耐药情况调查, 竟 也发现了抗药菌株, 说明HGT发生的地域广泛性。

\section{4. 常见牙周致病菌水平基因转移(HGT)与抗生 素抗性基因(ARGs)}

常见牙周致病菌根据口腔微生物群的定植和分布规 律及其与牙周状况的关系, 被划分为红、橙、黄、绿、紫、 
蓝六个微生物复合体, 其中与牙周病密切相关细菌包括: 伴放线聚集杆菌、牙龈卟啉单胞菌、福赛坦氏菌、齿垢密 螺旋体等 [8]。牙周治疗过程中抗生素的广泛应用促进了抗 生素耐药菌株的产生, HGT在ARG的传播过程中更是扮演 了重要角色, 菌斑生物膜中多样化的细菌种类和大量的胞 外DNA(extracellular DNA,eDNA)使菌斑中寄居的细菌通 过HGT进行基因交换的机会大大增加, 同时菌斑基质的结 构和性质也为维持稳定的抗生素浓度提供了极好的条件 $[23,33]$ 。最近的研究表明, 噬菌体介导的MGEs对于抗生 素耐药性在口腔内的传播至关重要 [34]。

\section{1. 牙龈口啉单胞菌（Porphyromonas gingivalis,P. gingivalis )}

牙龈卟啉单胞菌 ( Porphyromonas gingivalis, P.gingivalis）是引起牙周病的主要致病菌, 与牙周炎的发 展关系密切。P.gingivalis不同菌株间存在较大程度的遗传 变异, 种群结构可能是泛发性的, 说明菌株间可能存在 DNA 水平转移和重组。Tribble GD等[35]学者通过DNA克 隆、测序、PCR扩增、Southern杂交、大肠杆菌质粒纯化 等技术测试了 8 个P.gingivalis菌株, 发现其中有 5 个菌株能 够以接合作用的机制将整合了ARGs的质粒转移到大肠杆 菌中。Stuart等[36]学者在国际范围内选取P.gingivalis菌株 进行为期 25 年的研究, 对 13 株菌株进行了全基因组测序, 并与另外 10 株菌株进行了比较, 发现两组细菌在系统发育 基因组中有很高水平的网状交叉结构, 发现P.gingivalis菌 株间存在广泛的HGT。并且发现了P.gingivalis以HGT方式 进行结构域重排和遗传物质交换, 产生结构变异, 增加了 菌体表面毒力因子的多样性。

Ardila CM等[37]对当地76例诊断为慢性牙周炎的患 者的龈下标本进行培养并通过Etest法测定样本对阿莫西 林、甲硝唑、阿奇霉素和莫西沙星的敏感性。结果显示 P.gingivalis对莫西沙星敏感, 对阿莫西林 $(24.6 \%)$ 、阿奇霉 素 $(21.3 \%)$ 和甲硝唑 $(24.6 \%)$ 的耐药率相当, 该学者认为, P.gingivalis通过HGT的方式将质粒和染色体中的遗传物 质进行传播, 是其ARG发生传播的主要途径。

\section{2. 伴放线聚集杆菌 (Aggregatibacter} actinomycetemcomitans,A. actinomycetemcomitans )

伴放 线 聚 集杆菌 (Aggregatibacter actinomycetemcomitans, A.actinomycetemcomitans) 是牙 周疾病的重要致病菌, 尤其与侵袭性牙周炎 (AggressivePeriodontitis , AGP) 关系密切。 A.actinomycetemcomitans根据表面抗原不共分为 7 个血清 型（被命名为a-g）, 有学者通过对不同血清型菌株编码 白细胞毒素 (Leukotoxin, LTX)的操纵子分析, 认为不同血 清型间的差异可能是基因组中的各个区域在菌株之间水 平转移的频率不同。此外 $\mathrm{b}$ 型和 $\mathrm{c}$ 型菌株基因组整体结构的 差异, 可能是噬菌体和质粒DNA等DNA元件的插入不同 导致的 [38]。不同地域A.actinomycetemcomitans的耐药情 况存在较大差异。在对A.a的抗生素耐药性有关研究中, Ding Q等[39]通过对菌株进行全基因组分析, 按照血清型 将该物种分为五个分支, 并发现该物种所有基因组序列中
除核心基因外，不同菌株间还有特异性的可变基因（辅助 基因），而辅助基因通常形成具有碱基组成偏向可发生 HGT的MGEs, 这些MGEs促进了A.actinomycetemcomitans 抗性基因的传播。不同菌株间基因型和血清型的差异决定 了A.actinomycetemcomitans 菌株间的毒力异质性[39]。根 据该细菌通过同源重组从摄取的胞外DNA(extracellular DNA,eDNA）中获得新基因的能力差异, 分为能力菌株和 无能力菌株, 能力菌株能够通过转化摄取eDNA, 在修复 受体菌株DNA损伤、获得核苷酸和新的基因[40]的同时, 还促进了遗传的多样性。而无能力菌株在遗传上是稳定的, 需要通过接合质粒等进行菌株间的遗传物质交换[41]。虽 然两类菌株获取eDNA的能力存在差异, 但都发生了HGT, 促进了耐药基因的传播。

有学者通过回顾性比较基因组方法对 A.actinomycetemcomitans通过自然转化方式发生进化进行 了分析。研究发现, 有能力的感受态 A.actinomycetemcomitans 菌株有许多附加的群集规则间隔 短回文重复 ( clusteredregularly inter-spaced short palindromic repeat,CRISPR) 免疫系统, 可以保护细菌免受 寄生DNA的攻击, 相反, 非感受态的细菌由于失活突变而 失去了CRISPR免疫系统。由于非感受态菌株CRISPR介导 的免疫功能受损, 对噬菌体和质粒的识别更敏感, 更易发 生接合和转导，并由此介导了 HGT 的发生 [42]。 A.actinomycetemcomitans通过接合、转导和自然转化进行 的同源重组可以加快细菌对新环境的适应, 并使有机体更 快地达到适应性平衡 [43], 最近的几项研究探索了在口腔 中转录的CRISPR及其对入侵噬菌体的保护作用, 研究中 发现, 口腔噬菌体可能通过抗CRISPR蛋白来灭活细菌的 免疫系统, 抑制细菌清除噬菌体, 使得噬菌体在口腔中持 续存在, 促进了噬菌体介导的抗生素耐药基因转化和转导 的发生 $[44]$ 。

\section{3. 福赛坦氏菌（Tannerella forsythia, T. forsythia）}

福赛坦氏菌（Tannerella forsythia,T.forsythia）常见于 活动性重度牙周炎特别是吸烟患者口腔环境中, 有英国学 者 [37]对当地76例确诊有牙周炎患者的龈下微生物标本进 行培养分析, 对T.forsythia针对不同抗生素的耐药性进行 了测定, 结果表明, 43株T.forsythia中对莫西沙星敏感, 而对阿莫西林、阿奇霉素, 甲硝唑具有不同程度的耐药, 分别为 $25.6 \% 、 21.0 \%$ 和 $25.6 \%$ 。 Rams 等人 $[45]$ 还观察到 T.forsythia对阿莫西林的抗药性(15.8\%), 其他体外研究也 报道了该病原菌对四环素[46]和大环内酯类 [45, 47]的抗 药性。

T.f耐药机制源于其分泌了一种金属肽酶样酶 Karilysin, 该酶可以降解杀菌肽并促使宿主内相应补体失 活 [48，49]。通过系统发育和序列相似性研究表明, Karilysin的催化结构域Kly18 与其它细菌等微生物和哺乳 动物及有翼昆虫中的基质金属蛋白酶（MMPs）相比，与 哺乳动物及有翼昆虫中的MMPs更接近, 这表明Karilysin 基因是 $\mathrm{T}$. $\mathrm{f}$ 与人类或其他动物共生过程中通过HGT而获得 核心片段, 并通过不断进化演变成不同于动物MMPs的一 般多结构域 [49]。Karilysin和炭疽芽孢杆菌 (Bacillus 
anthracis,B.anthracis)编码的MMPZ是metzincin家族中仅有 的两个基质金属蛋白酶(MMP)家族成员，这种联系说明了 T.forsythia与B.anthracis异种菌株之间存在的密切联系, 并 提示两者遗传物质之间可能存在HGT[50]。

\section{4. 齿垢密螺旋体(Treponema denticola, T. denticola)}

齿垢密螺旋体(Treponema denticola,T.denticola)是与 牙周疾病密切相关的另一类庈氧牙周致病菌。它与人类牙 周病的发病率和严重程度有关。目前, T.denticola对四环 素类抗生素的耐药性已经明显显现, 有研究表明, 抗药基 因etB和ermF目前在T.denticola中广泛分布[51]。更重要的 观察结果是, 有 3 株T.denticola分离株能够将它们的ermF 决定簇通过 HGT 转移给给粪肠球菌受体 [52]。通过 $16 \mathrm{~S}$ rRNA基因测序比对发现，齿垢密螺旋体与猪、牛等动物 皮肤病变密切相关的足密螺旋体 (Treponema pedis,T.pedis) 具有共同的基因组特征、相似的功能类群分布, 并且在基 因内容上具有较高的同源性, 在系统发育上较为接近, 这 两种菌株有 $95.7 \%$ 的序列相似性, 包括保守的毒力相关基 因, 这表明它们之间有着密切的亲缘关系, 但同时发现了 两者存在同一物种的基因组中没有同源性的菌株特异性 基因, 这些基因很可能是通过HGT从周围微生物区获得的 $[53,54]$ 。Seshadri R等 [55]通过对T.denticola基因组序列进 行分析, 发现了 T.denticola与链球菌等口腔正常菌群存在 一些相同的三核苷酸组成的基因组区域, 说明了从 T.denticola到链球菌等口腔细菌可能存在质粒转移, 这也 暗示了 T.denticola可能通过HGT从其他口腔细菌获得遗传 物质。磷酰胆碱(phosphorylcholine, ChoP)参与了脂磷壁酸 (Lipoteichoic acid,LTA)的合成, 而脂磷壁酸(LTA)除了与 细菌毒性有关, 还是潜在的药物靶点, 因此, CHOP不仅 对于细胞壁的形成至关重要 [56], 而且潜在地促进了菌株 对于 $\beta$-内酰胺类药物的耐药性。有学者 [57]通过研究结果 表明, T.denticola具有一条独特的磷酰胆碱合成途径。该 途径上游编码基因胆碱磷酸转移酶基因只存在于梅毒螺 旋体在内的以及密螺旋体相关哺乳动物宿主。在对控制 CHOP合成的Cpt基因家族的分子测定分析表明, 密螺旋体 及梅毒螺旋体中的内胆碱磷酸转移酶基因是从原核宿主 有机体中通过HGT获得的。最近的一项对 T.denticola的基 因组序列分析中发现了一个大的整合子盒[58], 这是在革 兰氏阴性菌中变形杆菌外发现的第一个整合子,由于整合 子具有捕获、重排、表达和传播抗生素耐药基因的能力, 因此是HGT的理想载体, 该整合子可能赋予了 T.denticola 储存和传播抗生素抗性基因的特性。

\section{5. 粪肠球菌（Enterococcus faecalis，E. faecalis）}

粪肠球菌（Enterococcus faecalis , E.faecalis）近几十 年来已成为引起医院感染的主要机会性病原体 $[49,50]$ 。 E.faecalis并非人类口腔正常菌群中的一员 [59], E.faecalis 最初在难治性牙髓感染中被发现，但近年来在牙周炎、种 植体周围炎和根尖周炎等常见牙科疾病中发现了该细菌 $[60,61]$ 。E.faecalis对环境适应力和抵抗力强, 可耐受四环 素、卡那霉素、庆大霉素等多种抗生素, 近些年来, 随着
E.faecalis抗生素耐药性不断增强, 发现对曾经唯一敏感的 万古霉素也产生了耐药性。这使口腔感染的控制更加棘手。 除了拥有各种毒力和抗性基因外, E.faecalis还非常擅 长通过HGT来交换和传递其中许多基因, 在过去的十几年 中, 人们已经发现了E.faecalis不同菌株之间通过HGT进行 抗生素抗药基因转移[62], 以及从E.faecalis到金黄色葡萄 球菌(Staphylococcus aureus, S. aureus)的万古霉素耐药基 因转移 [63-65]。E.faecalis 产生抗药性的一种方式是通过 HGT获取抗药性基因。这些基因由MGEs传播, 包括整合 的接合元件, 如 $T n 916$, 广泛寄主范围的质粒, 以及一组 称为信息素响应质粒的窄寄主范围的质粒[66], 一般来说, 多重耐药E.faecalis菌株通过HGT获得的MGEs含量较丰富, 包括ARGs、VGs和对生态位扩展具有重要作用的代谢基 因 [67]。SunJ等 [68]学者调查了慢性牙周炎患者龈下 E.faecalis中毒力和耐药性状的存在及其决定因素, 在 10 个 菌株中检测到 $T n 916 / \mathrm{Tn} 1545$ 家族的整合酶基因和辅助基 因, 结果表明毒力和抗生素抗性决定因素在口腔E.faecalis 中普遍存在, 并且是毒力和抗菌素耐药性可移动元素的潜 在储存库, 质粒运动是E.faecalis 产生和传播抗生素抗药基 因的主要方式 [69]。在一项体外研究中, 以离体牙为载体 培育戈登链球菌和E.faecalis, 通过电镜扫描等手段, 证实 了携带红霉素抗性的接合质粒pAM81在2种细菌之间的双 向转移[70]。

\section{5. 总结与展望}

抗生素耐药机制及诸多研究结果表明, HGT推动了 牙周致病菌的抗生素耐药基因的获得和传播, 口腔环境 中, 菌斑生物膜作为牙周病的始动因素, 同时也是抗性 基因发生HGT的理想微环境, 因此, 菌斑生物膜机械清 除无论对于牙周病的防治还是对于降低口腔中抗性基因 的HGT发生率都具有重要意义。目前对于抗性基因在口 腔牙周致病菌之间发生HGT的研究取得了一些阶段性成 果, 通过基因组分析等方式发现了口腔感染性疾病的常 用抗生素的耐药机制及耐药基因, 并通过电镜扫描、 16SrRNA基因测序等手段发现了属内或属间通过HGT方 式发生了遗传物质的交换，但对于HGT发生的分子机制 通路还有待于进一步探究, 另一方面, 抗生素治疗牙周 病的替代方案的研发同样刻不容缓, 通过不断探究牙周 病的发病机制, 寻求牙周病治疗的有效手段, 对于我们 应对口腔致病菌的耐药问题, 优化牙周炎的治疗方案具 有重要的现实意义。

\section{利益冲突声明}

作者声明本文无利益冲突。

\section{致谢}

山东生自然科学基金面上项目（项目编号: ZR2020MH182), 济南市科技计划（后补助）项目（项 目编号：201907099、202019068）。 


\section{参考文献}

[1] Lei J, Sun L, Huang S, et al. The antimicrobial peptides and their potential clinical applications. American journal of translational research 2019: 11:3919-3931.

[2] Evans DR, Griffith MP, Sundermann AJ, et al. Systematic detection of horizontal gene transfer across genera among multidrug-resistant bacteria in a single hospital. eLife 2020: 9 .

[3] Juhas M, van der Meer JR, Gaillard M, Harding RM, Hood DW, Crook DW. Genomic islands: tools of bacterial horizontal gene transfer and evolution. FEMS microbiology reviews 2009: 33: 376-393.

[4] Jiang S, Zeng J, Zhou X, Li Y. Drug Resistance and Gene Transfer Mechanisms in Respiratory/Oral Bacteria. Journal of dental research 2018: 97: 1092-1099.

[5] Almeida VSM, Azevedo J, Leal HF, Queiroz ATL, da Silva Filho HP, Reis JN. Bacterial diversity and prevalence of antibiotic resistance genes in the oral microbiome. PloS one 2020: 15: e0239664.

[6] Chen R, Huangfu L, Lu Y, et al. Adaptive innovation of green plants by horizontal gene transfer. Biotechnology advances 2021: 46: 107671.

[7] Smillie CS, Smith MB, Friedman J, Cordero OX, David LA, Alm EJ. Ecology drives a global network of gene exchange connecting the human microbiome. Nature 2011: 480: 241-244.

[8] Socransky SS, Haffajee AD, Cugini MA, Smith C, Kent RL, Jr. Microbial complexes in subgingival plaque. Journal of clinical periodontology 1998: 25: 134-144.

[9] Lunsford RD. Streptococcal transformation: essential features and applications of a natural gene exchange system. Plasmid 1998: 39: 10-20.

[10] Tribble GD, Rigney TW, Dao DH, et al. Natural competence is a major mechanism for horizontal DNA transfer in the oral pathogen Porphyromonas gingivalis. mBio 2012: 3 .

[11] O'Neill S, O'Driscoll L. Metabolic syndrome: a closer look at the growing epidemic and its associated pathologies. Obesity reviews: an official journal of the International Association for the Study of Obesity 2015: 16: 1-12.

[12] Sommer MO, Dantas G. Antibiotics and the resistant microbiome Current opinion in microbiology 2011: 14: 556-563.

[13] Conlan S, Thomas PJ, Deming C, et al. Single-molecule sequencing to track plasmid diversity of hospital-associated carbapenemase-producing Enterobacteriaceae. Science translational medicine 2014: 6: 254ra126.

[14] Charpentier MJ, Fontaine MC, Cherel E, et al. Genetic structure in a dynamic baboon hybrid zone corroborates behavioural observations in a hybrid population. Molecular ecology 2012: 21: 715-731.

[15] Sørensen SJ, Bailey M, Hansen LH, Kroer N, Wuertz S. Studying plasmid horizontal transfer in situ: a critical review. Nature reviews Microbiology 2005: 3: 700-710.
[16] Pilla G, McVicker G, Tang CM. Genetic plasticity of the Shigella virulence plasmid is mediated by intra- and inter-molecular events between insertion sequences. PLoS genetics 2017: 13: e1007014.

[17] Hiller NL, Ahmed A, Powell E, et al. Generation of genic diversity among Streptococcus pneumoniae strains via horizontal gene transfer during a chronic polyclonal pediatric infection. PLoS pathogens 2010: 6: e1001108.

[18] Bañuelos-Vazquez LA, Torres Tejerizo G, Brom S. Regulation of conjugative transfer of plasmids and integrative conjugative elements. Plasmid 2017: 91: 82-89.

[19] Tamang MD, Sunwoo H, Jeon B. Phage-mediated dissemination of virulence factors in pathogenic bacteria facilitated by antibiotic growth promoters in animals: a perspective. Animal health research reviews 2017: 18: 160-166.

[20] Deng $\mathrm{Y}, \mathrm{Xu} \mathrm{H}, \mathrm{Su} \mathrm{Y}$, et al. Horizontal gene transfer contributes to virulence and antibiotic resistance of Vibrio harveyi 345 based on complete genome sequence analysis. BMC genomics 2019: 20: 761.

[21] Roberts AP, Kreth J. The impact of horizontal gene transfer on the adaptive ability of the human oral microbiome. Frontiers in cellular and infection microbiology 2014: 4: 124.

[22] Ramsay JP, Kwong SM, Murphy RJ, et al. An updated view of plasmid conjugation and mobilization in Staphylococcus. Mobile genetic elements 2016: 6: e1208317.

[23] Roberts AP, Mullany P. Oral biofilms: a reservoir of transferable, bacterial, antimicrobial resistance. Expert review of anti-infective therapy 2010: 8: 1441-1450.

[24] Lunde T. Investigation of the prevalence of Tn916/Tn916-like elements in oral streptococci. Journal of oral microbiology 2017: 9

[25] Pride DT, Salzman J, Haynes M, et al. Evidence of a robust resident bacteriophage population revealed through analysis of the human salivary virome. The ISME journal 2012: 6: 915-926.

[26] Liao S, Klein MI, Heim KP, et al. Streptococcus mutans extracellular DNA is upregulated during growth in biofilms, actively released via membrane vesicles, and influenced by components of the protein secretion machinery. Journal of bacteriology 2014: 196: 2355-2366.

[27] Gaetti-Jardim EC, Marqueti AC, Faverani LP, Gaetti-Jardim E, Jr. Antimicrobial resistance of aerobes and facultative anaerobes isolated from the oral cavity. Journal of applied oral science: revista FOB 2010: 18: 551-559.

[28] Arredondo A, Blanc V, Mor C, Nart J, León R. Resistance to $\beta$-lactams and distribution of $\beta$-lactam resistance genes in subgingival microbiota from Spanish patients with periodontitis. Clinical oral investigations 2020: 24: 4639-4648.

[29] Ramos MM, Gaetti-Jardim EC, Gaetti-Jardim Junior E. Resistance to tetracycline and $\beta$-lactams and distribution of resistance markers in enteric microorganisms and pseudomonads isolated from the oral cavity. Journal of applied oral science: revista FOB 2009: 17 Suppl: 13-18. 
[30] Cerdá Zolezzi P, Laplana LM, Calvo CR, Cepero PG, Erazo MC, Gómez-Lus R. Molecular basis of resistance to macrolides and other antibiotics in commensal viridans group streptococci and Gemella spp. and transfer of resistance genes to Streptococcus pneumoniae. Antimicrobial agents and chemotherapy 2004: 48: 3462-3467.

[31] Haggoud A, Reysset G, Azeddoug H, Sebald M. Nucleotide sequence analysis of two 5-nitroimidazole resistance determinants from Bacteroides strains and of a new insertion sequence upstream of the two genes. Antimicrobial agents and chemotherapy 1994: 38: 1047-1051.

[32] Xie Y, Chen J, He J, et al. Antimicrobial resistance and prevalence of resistance genes of obligate anaerobes isolated from periodontal abscesses. Journal of periodontology 2014: 85: 327-334.

[33] Marsh PD. Plaque as a biofilm: pharmacological principles of drug delivery and action in the sub- and supragingival environment. Oral diseases 2003: 9 Suppl 1: 16-22.

[34] Lugli GA, Milani C, Turroni F, et al. Prophages of the genus Bifidobacterium as modulating agents of the infant gut microbiota. Environmental microbiology 2016: 18: 2196-2213.

[35] Tribble GD, Lamont GJ, Progulske-Fox A, Lamont RJ. Conjugal transfer of chromosomal DNA contributes to genetic variation in the oral pathogen Porphyromonas gingivalis. Journal of bacteriology 2007: 189: 6382-6388.

[36] Dashper SG, Mitchell HL, Seers CA, et al. Porphyromonas gingivalis Uses Specific Domain Rearrangements and Allelic Exchange to Generate Diversity in Surface Virulence Factors. Frontiers in microbiology 2017: 8: 48.

[37] Ardila CM, Bedoya-García JA. Antimicrobial resistance of Aggregatibacter actinomycetemcomitans, Porphyromonas gingivalis and Tannerella forsythia in periodontitis patients. Journal of global antimicrobial resistance 2020: 22: 215-218.

[38] Jorth P, Whiteley M. An evolutionary link between natural transformation and CRISPR adaptive immunity. mBio 2012: 3.

[39] Kittichotirat W, Bumgarner RE, Asikainen S, Chen C. Identification of the pangenome and its components in 14 distinct Aggregatibacter actinomycetemcomitans strains by comparative genomic analysis. PloS one 2011: 6: e22420.

[40] Ahlstrand T, Torittu A, Elovaara H, et al. Interactions between the Aggregatibacter actinomycetemcomitans secretin HofQ and host cytokines indicate a link between natural competence and interleukin-8 uptake. Virulence 2018: 9: 1205-1223.

[41] Ding Q, Tan KS. Himar1 Transposon for Efficient Random Mutagenesis in Aggregatibacter actinomycetemcomitans. Frontiers in microbiology 2017: 8: 1842.

[42] Zhou H, Zhao H, Zheng J, et al. CRISPRs provide broad and robust protection to oral microbial flora of gingival health against bacteriophage challenge. Protein \& cell 2015: 6: 541-545.

[43] Wylie CS, Trout AD, Kessler DA, Levine H. Optimal strategy for competence differentiation in bacteria. PLoS genetics 2010 : 6: e1001108.
[44] Maxwell KL. Phages Fight Back: Inactivation of the CRISPR-Cas Bacterial Immune System by Anti-CRISPR Proteins. PLoS pathogens 2016: 12: e1005282.

[45] Rams TE, Dujardin S, Sautter JD, Degener JE, van Winkelhoff AJ. Spiramycin resistance in human periodontitis microbiota. Anaerobe 2011: 17: 201-205.

[46] Dahlen G, Preus HR. Low antibiotic resistance among anaerobic Gram-negative bacteria in periodontitis 5 years following metronidazole therapy. Anaerobe 2017: 43: 94-98.

[47] Lakhssassi N, Elhajoui N, Lodter JP, Pineill JL, Sixou M. Antimicrobial susceptibility variation of 50 anaerobic periopathogens in aggressive periodontitis: an interindividual variability study. Oral microbiology and immunology 2005: 20: 244-252.

[48] Skottrup PD, López R, Ksiazek M, et al. An IgY-based immunoassay to evaluate the biomarker potential of the Tannerella forsythia virulence factor karilysin in human saliva. Journal of immunological methods 2019: 469: 26-32.

[49] Cerdà-Costa N, Guevara T, Karim AY, et al. The structure of the catalytic domain of Tannerella forsythia karilysin reveals it is a bacterial xenologue of animal matrix metalloproteinases. Molecular microbiology 2011: 79: 119-132.

[50] Guevara T, Ksiazek M, Skottrup PD, et al. Structure of the catalytic domain of the Tannerella forsythia matrix metallopeptidase karilysin in complex with a tetrapeptidic inhibitor. Acta crystallographica Section F, Structural biology and crystallization communications 2013: 69: 472-476.

[51] Roberts MC, Chung WO, Roe DE. Characterization of tetracycline and erythromycin resistance determinants in Treponema denticola. Antimicrobial agents and chemotherapy 1996: 40: 1690-1694.

[52] Fenno JC. Treponema denticola interactions with host proteins. Journal of oral microbiology 2012: 4.

[53] Svartström O, Mushtaq M, Pringle M, Segerman B. Genome-wide relatedness of Treponema pedis, from gingiva and necrotic skin lesions of pigs, with the human oral pathogen Treponema denticola. PloS one 2013: 8: e71281.

[54] Vences-Guzmán M, Paula Goetting-Minesky M, Guan Z, et al. 1,2-Diacylglycerol choline phosphotransferase catalyzes the final step in the unique Treponema denticola phosphatidylcholine biosynthesis pathway. Molecular microbiology 2017: 103: 896-912.

[55] Seshadri R, Myers GS, Tettelin H, et al. Comparison of the genome of the oral pathogen Treponema denticola with other spirochete genomes. Proceedings of the National Academy of Sciences of the United States of America 2004: 101: 5646-5651.

[56] Denapaite D, Brückner R, Hakenbeck R, Vollmer W. Biosynthesis of teichoic acids in Streptococcus pneumoniae and closely related species: lessons from genomes. Microbial drug resistance (Larchmont, NY) 2012: 18: 344-358.

[57] Khalifa M, Few LL, See Too WC. ChoK-ing the Pathogenic Bacteria: Potential of Human Choline Kinase Inhibitors as Antimicrobial Agents. BioMed research international 2020: 2020: 1823485 . 
[58] Coleman N, Tetu S, Wilson N, Holmes A. An unusual integron in Treponema denticola. Microbiology (Reading, England) 2004: 150: 3524-3526.

[59] Lee D, Im J, Na H, Ryu S, Yun CH, Han SH. The Novel Enterococcus Phage vB_EfaS_HEf13 Has Broad Lytic Activity Against Clinical Isolates of Enterococcus faecalis. Frontiers in microbiology 2019: 10: 2877.

[60] Delboni MG, Gomes BP, Francisco PA, Teixeira FB, Drake D Diversity of Enterococcus faecalis Genotypes from Multiple Oral Sites Associated with Endodontic Failure Using Repetitive Sequence-based Polymerase Chain Reaction and Arbitrarily Primed Polymerase Chain Reaction. Journal of endodontics 2017: 43: 377-382.

[61] Bohora AA, Kokate SR, Khedkar S, Vankudre A. Antimicrobial activity of probiotics against endodontic pathogens:- A preliminary study. Indian journal of medical microbiology 2019: 37: 5-11.

[62] Anderson AC, Jonas D, Huber I, et al. Enterococcus faecalis from Food, Clinical Specimens, and Oral Sites: Prevalence of Virulence Factors in Association with Biofilm Formation. Frontiers in microbiology 2015: 6: 1534.

[63] Dahmane N, Libante V, Charron-Bourgoin F, et al. Diversity of Integrative and Conjugative Elements of Streptococcus salivarius and Their Intra- and Interspecies Transfer. Applied and environmental microbiology 2017: 83 .

[64] Barros J, Melo LDR, Poeta P, et al. Lytic bacteriophages against multidrug-resistant Staphylococcus aureus, Enterococcus faecalis and Escherichia coli isolates from orthopaedic implant-associated infections. International journal of antimicrobial agents 2019: 54: 329-337.

[65] Kang ZZ, Lei CW, Kong LH, et al. Detection of transferable oxazolidinone resistance determinants in Enterococcus faecalis and Enterococcus faecium of swine origin in Sichuan Province, China. Journal of global antimicrobial resistance 2019: 19: 333-337.
[66] Clewell DB, Weaver KE, Dunny GM, Coque TM, Francia MV, Hayes F. Extrachromosomal and Mobile Elements in Enterococci: Transmission, Maintenance, and Epidemiology. In: Gilmore MS, Clewell DB, Ike Y, Shankar N, ed. Enterococci: From Commensals to Leading Causes of Drug Resistant Infection. Boston: Massachusetts Eye and Ear Infirmary, 2014.

[67] Huo W, Adams HM, Zhang MQ, Palmer KL. Genome Modification in Enterococcus faecalis OG1RF Assessed by Bisulfite Sequencing and Single-Molecule Real-Time Sequencing. Journal of bacteriology 2015: 197: 1939-1951.

[68] Sun J, Sundsfjord A, Song X. Enterococcus faecalis from patients with chronic periodontitis: virulence and antimicrobial resistance traits and determinants. European journal of clinical microbiology \& infectious diseases: official publication of the European Society of Clinical Microbiology 2012: 31: 267-272.

[69] Manson JM, Hancock LE, Gilmore MS. Mechanism of chromosomal transfer of Enterococcus faecalis pathogenicity island, capsule, antimicrobial resistance, and other traits. Proceedings of the National Academy of Sciences of the United States of America 2010: 107: 12269-12274.

[70] Sedgley CM, Lee EH, Martin MJ, Flannagan SE. Antibiotic resistance gene transfer between Streptococcus gordonii and Enterococcus faecalis in root canals of teeth ex vivo. Journal of endodontics 2008: 34: 570-574.

\section{作者简介}

李建斌, 硕士研究生在读, 口腔医学住院医师, 研究方 向为PLAP-1在䍜患系统性基础疾病 (骨质疏松症、糖尿 病）牙周炎中的作用机制。

于西佼, 口腔医学博士, 副教授, 主要研究内容为牙周 病相关骨代谢机制的研究。 